\title{
(息)
}

Citation:

Ross, SL (2014) What is ambiguous about ambiguous goods? Journal of Consumer Behaviour, 13 (2). 140 - 147. ISSN 1472-0817 DOI: https://doi.org/10.1002/cb.1454

Link to Leeds Beckett Repository record:

https://eprints.leedsbeckett.ac.uk/id/eprint/1342/

Document Version:

Article (Accepted Version)

The aim of the Leeds Beckett Repository is to provide open access to our research, as required by funder policies and permitted by publishers and copyright law.

The Leeds Beckett repository holds a wide range of publications, each of which has been checked for copyright and the relevant embargo period has been applied by the Research Services team.

We operate on a standard take-down policy. If you are the author or publisher of an output and you would like it removed from the repository, please contact us and we will investigate on a case-by-case basis.

Each thesis in the repository has been cleared where necessary by the author for third party copyright. If you would like a thesis to be removed from the repository or believe there is an issue with copyright, please contact us on openaccess@leedsbeckett.ac.uk and we will investigate on a case-by-case basis. 
Title: What is Ambiguous about Ambiguous Goods? 


\title{
What is Ambiguous about Ambiguous Goods?
}

\begin{abstract}
10 Ambiguous goods are not a category of things. No goods are ambiguous by default, not even digital virtual ones. Ambiguity may arise in many ways, but this article examines one specific process: ambiguity that occurs when entities appear as objects that blur category boundaries. Ambiguity is created around pre-existing categories through socio-material entanglements. This article explores how a central category in consumer capitalist societies - property - takes on ambiguous forms in

15 distributions and recirculations of prestige items in the massively multi-player online role-playing game Final Fantasy XI (FFXI). Prestige objects are powerful, sought-after armour and weapons acquired in the game world by completing difficult battlefields or tasks, often in large groups. When discussing these items, respondents are not confused actors trying to make sense of slippery things. Instead, they produce ambiguities around property by blurring distinctions between gifts and commodities. Blurred

20 boundaries help resolve tensions arising from different orderings of people, relations and things. Hybridised property forms allow selective alienation of goods, allowing participants to privilege some relations and connections over others.

With this article I hope to spark further debate on building a conceptual toolkit to explore ambiguities, 25 and contribute to increasing interest in non-dyadic gift relations in consumer culture research. 'Ambiguous goods' is not a viable category for thinking about things, people and relations or digital virtual objects. But ambiguity can be a useful way to think about how people and things - whether they are digital, virtual or neither - are related.
\end{abstract}

30

Key words: ambiguous goods, property, gifts, commodities, digital virtual goods, Final Fantasy XI
Abstract word count: 246
Body word count: 6614 


\section{What is Ambiguous about Ambiguous Goods?}

40 There are no ambiguous goods, yet all objects are at some point, in some way, ambiguous. No objects, even digital virtual ones, are ambiguous by default. Ambiguous goods are not a category, but this idea becomes analytically useful only when we explore how objects become uncertain. Instead of being a category, ambiguity is better conceived as being generated around already existing categories, produced through socio-material processes and interactions involving object, human and network agency -

45 though this paper focuses on human agency. This paper offers one example of ambiguity created around a culturally central category in consumer capitalist societies, property, in a nearly ideal typical case of digital virtual goods (Denegri-Knott and Molesworth, 2012:2-4) - prestige objects in the virtual world of Final Fantasy XI (FFXI) - bringing together anthropological work on property forms (Strathern, 1996a, 1996b, Kopytoff, 1986; Bird-David and Darr, 2009; Mauss, [1954]1970) and

50 divestment (Strathern, 1999; see also Parsons and MacLaren, 2009), and consumer culture literature on possessions (Marcoux 2001; Epp and Price 2009) and digital virtual goods (Slater 2002; Denegri-Knott and Molesworth 2012; Ross 2012).

As digital virtual objects in a proprietary, pay-to-play virtual world, FFXI's prestige items are almost

55 ideal type examples of 'ambiguous goods', objects that might be categorised as ambiguous by default because they are associated with digital, networked technologies; or because they exist primarily within a virtual world (Slater 2002; Lehdonvirta 2010). If prestige objects in FFXI were innately ambiguous, respondents would struggle to categorise them. Instead, research participants used prestige goods to produce ambiguities by blurring boundaries between two categories: gift and commodity. These

60 contingent hybridisations are not new categories so much as temporary fixes creating a patchwork binding people, things and relations. These compromises create partial connections (Strathern 1991; 
Law and Mol 1995) between different orderings of entire worlds or ontologies. In FFXI, players do not struggle to categorise objects, but to join fractal worlds and maintain semblances of material and social order, because categories may seem to be shared, but their forms vary.

65

Thinking of ambiguous goods as a category risks obscuring how ambiguities are produced, maintained and resolved. Ambiguous goods as a category makes it difficult to ask what qualities of things are ambiguous; what is meant by ambiguity; how ambiguousness is produced through socio-material entanglements; and how objects, people and assemblages resist, facilitate or maintain ambiguities. In

70 this paper, ambiguity means boundaries have become blurred between identifiable, conceptuallyrelated categories, like gift and commodity, which are are imagined as distinct, and sometimes oppositional, property forms implying different orderings of social relations and obligations (Mauss, 1970; Carrier, 1991, 1995; Strathern 1999; Weiner 1980; Kopytoff, 1986; see also: Marcoux, 2001; Giesler and Pohlmann, 2003; Epp and Price, 2009; Belk 2010; Belk at al, 2004). Framing ambiguity as

75 a concept allows us to ask what categories are being altered; why these particular categories; and how things, people and relations are classified, maintained and mutually constituted. In FFXI, making sense of an object as both gift and commodity rather than one form or the other allows players to be selective about who is connected to them through objects and who is not. Transferable prestige goods lend themselves to these selective alienation efforts as they have qualities that can be linked to both property

80 forms. ${ }^{i}$ These items are generated through collective labour, circulate within dense socio-material networks and are part of a larger category of goods of which the majority are inalienable - qualities resembling ceremonial exchange or gift-like objects (Weiner 1980, Carrier 1995). Transferable prestige goods have commodity-like features also: they are fungible, alienable and exchanged amongst anonymous transactors (Carrier 1995). 
I am also concerned about the possibility of thinking about digital virtual goods as somehow ambiguous by default, or considering ambiguity as a special quality of such objects. New technologies do not necessarily mean new categories or property forms (Slater 2002). We must attend to actors' and objects' interactions that reshape, reproduce and maintain already existing categories. Digital virtual

90 objects - as opposed to virtual things like the Eucharist (Shields, 2003:6) or indulgences - present themselves in social and technological interstices, but they are not an altogether new form of materiality (Slater, 2002). These technologies bring together actors with diverse ontologies. In Final Fantasy XI, ambiguous property forms arise from multiple orderings and ontologies that are enacted through shared practices. Actors must make partial connections (Strathern, [1991]2005) between

95 disparate worlds, piecing together a shared world with space for multiple ontologies. This is also not a matter of technology creating new kinds of unclassifiable things, people or relations. Instead, we have actors using digital virtual entities that they perceive as 'just lines in a database', as interviewee Squiggle said, to create ambiguous property forms.

100 I hope this paper sparks further efforts to refine the concept of ambiguous goods by exploring blurred boundaries, particularly those relevant to key concepts in consumer capitalist societies, such as property and its subcategories, gift and commodity. Property is a central anthropological preoccupation, and this paper engages with established literatures on property forms, categories and relations. I am concerned by a narrow, dyadic framing of gift relations in studies of consumer culture (Carrier 1991;

105 Giesler 2006), which does not at all reflect either foundational anthropological work on gifts and gift exchange systems (Mauss [1954]1970) nor contemporary debates on gifts, kinship and relatedness, which emphasise multiplicities and networks of relations between people and things (Strathern 1996a, 1996b, 1999; Weiner 1980; Holbraad 2011). Insofar as it explores ambiguities around gift and commodity categorisations, this work also supports Bird-David and Darr's (2009) tentative exploration 
110 of objects that are simultaneously gift and commodity. Finally, this paper also offers examples of ontological multiplicity in action (Strathern [1991]2005; Law 2011; Law and Mol,1995) showing fractal worlds partially, contingently connected through the efforts of people and things in relation.

\section{Methods and Fieldsites}

115 This paper is based on over eight years of engagement with Final Fantasy XI players. There were two participant observation periods - 2003-2005 and 2006-2008 - involving multiple linkshells (player-run organisations like guilds in other online games), including Yukikaze, Azalea, OotakaraNakama, Sleipnir and Gobbue. Empirical materials are mostly from Sleipnir and Azalea, but include informants from other groups. In addition to thirty-two one-on-one qualitative interviews in 2005, and thirty-seven

120 from 2007-2009, I also conducted nine panel interviews with respondents who regularly played together. All names are pseudonyms. Most fieldwork was conducted in English; some discussions were in French or Japanese. Transcripts and field notes were coded manually and indexed by theme or concept. Some central or frequently repeated themes and ideas were cross-indexed.

125 Final Fantasy XI is a game-oriented virtual world with an international player base. It is owned and maintained by Square-Enix, a Japanese corporation. Users create a character and devote hundreds of hours to developing its skills and powers. Players may participate in multiple linkshells at the same time, a distinctive feature of FFXI. Linkshell members co-operate to earn powerful weapons and armour, generated by killing monsters and referred to as drops (slain monsters 'drop' items they

130 carried). Creatures generating prestige goods are elusive. Some appear every seventy-two hours, others spawn under particular conditions (e.g. during a certain virtual weather condition or upon completing quests). Most prestige objects are not generated reliably, multiple victories may be needed to gain desired items. Drop allocation rules are listed on linkshell websites, and are tied to points systems. 
Players earn points by participating in scheduled events and helping other linkshell members.

135 Voluminous forum, website and blog postings about regulations include conduct and attendance guidelines, linkshell philosophies and myriad social, economic and material details. Yet linkshell leaders and organisers who produce these documents refrain from codifying property rights.

New prestige goods are introduced regularly. In 2003, few prestige goods were non-transferable. By

140 2008, about half of prestige items were inalienable, and by 2012 most could not be transfered. This paper's ethnographic present is during this transition, between a time when recirculation of wealth was normative for many players and one where recirculation became quite difficult. Transferable prestige goods are a declining population of things in FFXI, partly because of player complaints about itemrelated conflicts. Some objects in this paper are transferable prestige goods, some are inalienable.

\section{Conceptual Background}

In consumer capitalist societies, property produces ambiguities because it is relations, owning and disowning people, relations, things; and rights, disposition, usufruct or possession (Strathern, 1999:140-141). Property forms constitute 'Euro-American views of what is appropriate to relations

150 between people and things' (Strathern 1999:4). When FFXI players disagree over who may give, make claims or receive, they are having ontological disputes. Judgements about the appropriateness of claims are judgements about who and what should be related (Strathern, 1996a; Carrier, 1991; Douglas and Isherwood, [1979]1996). These are moments where partial connections (Strathern [1991]2005; Law and Mol 1995) painstakingly negotiated and maintained through shared practices, may fall apart.

Few things exist in FFXI that are neither property nor about to become property - monsters and players excepted. Drops reside in collective loot pools for only moments before being allocated to a player. In 
this liminal time, items are becoming-property whilst party members carry out previously agreed allocations, cast lots or negotiate. The contentious issue in FFXI is not whether an object is property,

160 but how it is property (Strathern 1999:18). For example, objects crafted by another player are perceived as closer to commodities than gifts because they are alienable and fungible - though purchased prestige goods confer less status than earned items.

Once I receive a commodity, it is mine to do with as I please. . . Those involved with the commodity's production or with the transaction in which I acquired it have no claim on me once the transaction is completed. (Carrier, 1995:33).

Dispositional rights accrue to possessors of commodity-like objects, not to alienated linkshell members, friends and fictive kin, who have no basis for property claims.

170 Drops generated with friends' help lean toward classification as gifts. Such objects are embedded in dense socio-material networks characterised by relations of obligation (Ross, 2012), which often extend into other game worlds (e.g.: League of Legends, Half-Life) or everyday exchanges (e.g.: buying pizza, carpooling).

... in gift relations people are not free, autonomous individuals, but moral persons, identified and bound by the relations in which they exist. (Carrier 1995:158)

Members may feel they have claims on wealth they helped produce because these objects flowed to their possessors through relations between that person, the object (and previous drops), the linkshell and its members (Strathern, 1999; Weiner, 1980). When items are recirculated - especially if the holder

180 is leaving FFXI - some players believe objects should return along the routes through which they came, affirming the 'effectiveness of relationships' (Strathern, 1999:16) within the group. Such relations are neither dyadic nor directly reciprocal.

Giesler (2006:286) has observed similar gift-like relations amongst peer-to-peer music sharers. 
Napster seems to reflect an ideological transition from music ownership (property) to music access (gift). At [sic] Napster, it is not important to own the copyright but to have unlimited access to a web of shared music.

Unlike digital music files, prestige goods in FFXI cannot be duplicated, and each object is embedded in

190 its own singularised history (Carrier, 1995; Kopytoff, 1986) and relations (Weiner, 1980). This example from digital music sharing suggests a shift from alienable personal property toward shared public good. But in FFXI, ambiguous property forms are not necessarily indicative of novel understandings of property. Respondents' accounts include collective wealth, ownership as access to a shared good, or access as gift (which can be rescinded or bestowed elsewise), which have echoes in peasant resistance

195 to enclosures of the commons in 16th and 17th century England (Linebaugh and Rediker, 2000:15-25) and 18th century corn riots (Thompson, 1971:83).

Commodity and gift are 'ideal polar types, and no economic system could conform to either' (Kopytoff 1986:69-70), yet these categories are often positioned as 'fundamentally contrastive and mutually 200 exclusive' (Appadurai, 1986:11). Objects may transition between gift and commodity during their biographies (Kopytoff 1986; Carrier 1995:112-114), but may not be both simultaneously. Divisions between gift and commodity recreate another false dichotomy: economy and society, or economy and culture (Slater 2002). Gift and commodity are not mutually exclusive (Bird-David and Darr, 2009), but are different ends of a spectrum of property forms. Most objects in FFXI, as in everyday life, are

205 clustered at the extremes of this continuum. Commodity-like objects may be made-to-order by a linkshell craftsman from materials earned through group effort. Gift-like objects may be gained by paying strangers to help kill a monster, or by paying a group for drops they do not need or want. Prestige goods' qualities and engagements with people, not their substance, facilitate blurring category boundaries. Both things and people exercise agency in generating ambiguities, though the example

210 featured in this article focuses on human action. 
Property implies entire worlds, and in FFXI these worlds are multiple; objects participate in multiple simultaneous framings and categorisations. Users from disparate regions (Japan, Asia, the Americas, Europe), using different devices (gaming consoles, desktop PCs), had staggered entries to FFXI,

215 sometimes years apart. Japanese players arrived first and developed practices, particularly in elite linkshells, that later arrivals emulated. With each new wave of users, existing practices and categories were modified to suit different ontologies. Law and Mol (1995:290), borrowing from Strathern ([1991]2005), argue that such multiplicity is not

... isolated and fragmented worlds. Instead. . . there are partial connections. Partial and varied connections between sites, situations and stories. This, then, is the patchwork option. It's to imagine that materials and social - and stories too - are like bits of cloth that have been sewn together.

Following this metaphor, ambiguous property forms are one of many threads that bind different

225 ontologies, creating shared worlds from fractal ones. Law (2011) describes plural, juxtaposed worlds as 'fractiverse[s]', which he rejects in favour of 'contingent and heterogeneous enactments, performances or sets of relations'. Fractiverses and contingency may not be incompatible. Ambiguous property forms are contingent and temporary, but the shared worlds they facilitate by smoothing over ontological differences are relatively stable and enduring. To be a FFXI player is to be a negotiator, to understand

230 that all players do not interpret categories in the same ways, and to accept that objects, people and relations are multiply ordered. Ambiguous property forms create partial, contingent connections between acknowledged and enduring fractal worlds.

\section{Both Gift and Commodity}

235 Objects that become property may be simultaneously gift and commodity (Bird-David and Darr 2009). This section shows how FFXI prestige goods take on qualities of gifts and commodities through their 
interactions and entanglements with people and other objects. Prestige goods' property forms depend upon the world a player has built around herself, the relations she believes exist between this object, her, and other people and objects, and forms of agency and interaction ascribed to things and people.

240 Property forms demonstrate the quality of relations players produce and maintain, especially in magnanimous prestations (Strathern, 1999:16). In FFXI leavers' divestments, magnanimity is enacted by blurring boundaries between gift and commodity, permitting recipients to reproduce relations and orderings of people and things as required. Such performances require tractable objects, things that are desirable as gifts and alienable. Telling a friend they may sell an expensive object or keep it affirms

245 respondents' commitment to relations and people over digital virtual objects. For many players, asymmetrical privileging of people over things constitutes a locally desirable rejection of instrumental attitudes. Rain, an enthusiastic collector in FFXI, describes his treasures as 'mere Bits \& Bytes :D', comparing prestige items to snack food (Bits \& Bites).

250 In panel interviews, I asked players whether items received through linkshells were better understood as wages or as gifts (these designations were used by respondents in participant observation). Two responses to this question show different blurring of gift and commodity categories. These interviewees from Sweden, Australia, Puerto Rico, Canada and the United States have all been Sleipnir members.

Lodegrance: yeah maybe both, or maybe not like that at all. I mean the LS works together to get the stuff. You don't work for someone and get something back. Lair: almost every LS has a points system to make sure you worked hard to get the item you wanted, that's mostly to stop people from being greedy. Really a LS needs to work as a group, and the game is more fun when you're all friendly then fighting over items. There are LSs without points systems that function fine because they know their members well and are always trying to help each other. Kaido: you don't work FOR someone, but rather WITH someone. Lair: Lot[s] of people play FFXI to get a good character, to have good gear and be good at a job. But really its the most fun to work together with people you know and cooperate. I'd much rather be playing FFXI with a bunch of my friends all helping each other and me with bad gear then having the best gear and no-one wanting to help me. 
Lodegrance's comment reflects the challenges of working in diverse groups for weeks, months, even years. In linkshells there are people towards whom players do not mind being obliged and connected -

270 friends, fictive kin - and others they tolerate on sufferance. But players must co-operate even with people they dislike. Characterising drops as 'pure' gifts would place players in unwilling relations of obligation and reciprocity with all group members. Yet making drops appear as commodities implies alienated things and instrumentally motivated people, as in Lair's nightmare scenario. For Lair, having friends who help one another is more important than having digital virtual wealth.

275

Kaido emphasises ‘working with' not 'for', embedding prestige goods in co-operative relations, yet he disagrees that sociability is more important than prestige goods.

Kaido: I think both parts [wealth and friendships] are essential Lair, otherwise there's no point in playing. You lose one of them and you get tired of playing. . . Lair: if your gear is never moving forward what[']s the fun? But I think what I'm trying to say is people often get too caught up on the item side of things

Kaido and Lair's exchange draws on long-standing debates about balancing different orderings of people, things and relations in FFXI. For Lair, obsession with 'good gear' disrupts social relations,

285 echoing sociological concerns about materialism and social cohesion (Durkheim [1902]1960; Bauman 2001; see Trentman, 2009 for critique). Kaido argues both orientations are needed. Framing prestige items this way balances tensions between players focused on accumulating wealth and those who prioritise relationships. Ambiguity wraps goods in a protective fog, circumventing corrosive instrumentality associated with commodity/wage formulations and potential stagnation from over290 emphasis on sociability.

Shukudai, Riddaraan and Qanael initially disagreed about prestige item property forms. Shukudai says these goods are not gifts, but Riddaraan disagrees, based on his experience with Wyrmal Abjuration 
(Legs). Wyrmal Abjuration (Legs) is an abjuration traded to a non-player character, along with Cursed

295 Cuisses, to produce Crimson Cuisses. Cursed Cuisses are alienable objects crafted by characters with advanced alchemical skills. W.Legs and Crimson Cuisses are non-transferable.

Shukudai: Closer to 'wage' than to 'gift'. You can't call it a 'gift' if you work towards it, now can you. I went to work for 8 hours, the boss 'gifted' me 8 hours of pay.

Riddaraan: Although it's kind of like, your 'wages' can be usurped by someone else in the same department. We have this awesome example that I love to talk about going on in our LS right now. I feel I've been working, overall, decently hard, as often as I can be on, to earn points for an item in sky, Wyrmal Legs. And yet, when I try to cash my 'paycheck' others nullify my work and say, 'me first!' Qanael: Well, there's only so many W.Legs that drop, and oh so many people that want them.

Shukudai: They are spending their 'credit', that they saved up for said item. Just gotta wait.

Riddaraan: The difference with a paycheck and the way points work is that the bank is open 5 days a week, with a nearly limitless supply of money. That's all I'm saying. You can't cash your 'paycheck' when you want.

Having accumulated enough points, Riddaraan should be eligible receive W.Legs according to Sleipnir's rules. His accusation of favouritism implicates Qanael, one of Sleipnir's junior leaders.

Qanael argues poor supply and high demand are the problem, reinforcing a wage/commodity framing.

315 Shukudai emphasises appropriate claims and credit. This is the conversation's turning point, when W.Legs may take form as both gift and commodity. Relations of mutual obligation characterise gift economies (Carrier 1995; Strathern 1999:16-20), but legal frameworks of rights and obligations are central to contractual relations and commodity forms in contemporary consumer capitalist societies. Shukudai has bridged Riddaraan's and Quanael's different worlds, with different relations between W.Legs and Sleipnir members, the linkshell as a whole, and those who receive or are excluded from digital virtual wealth. Riddaraan builds on this compromise, suggesting virtual prestige items may be like wages, but multiple claims and priorities require negotiation, which interferes with a direct commodified-labour-to-wage relationship. He neither accepted nor entirely rejected Shukudai's both/and framing. Blurring gift and commodity categories legitimises Riddaraan’s sense of being 
325 unrewarded and explains why he has been passed over. Shukudai's effort to render these categories ambiguous makes partial connections that avert an argument between Quanael and Riddaraan.

When BigWig quit FFXI, he gave his Maneater axe to Jagermeister. These friends had never met in person, but played FFXI and Half-Life together for many years.

BigWig: man u can keep this[,] sell it whatever Jagermeister: sweet!!

BigWig: if u need diff[erent] stuff sell. just take \& use or make gil. i want u to have it Jagermeister: lol dont need 2 tell me 100x

335 They generated the axe together, and now that BigWig is leaving, Maneater flows back along that relationship to Jagermeister, affirming their friendship. By making the form Maneater should take ambiguous - potentially commodity or cherished gift - BigWig offers Jagermeister the possibility of later reinterpreting the form of this object without changing the nature of the relationship it continues to reproduce and maintain. Giving the axe to Jagermeister is more important than what happens to it

340 afterwards. Like Kaido, who argues both instrumental and sociable relations are needed in a linkshell, and like Shukudai, who introduces the possibility that W.Legs can be wage and gift, BigWig blurs boundaries between categories. Ambiguity for Kaido, BigWig, Shukudai and other FFXI players arises from socio-material entanglements and actors' efforts to maintain relations between people and things.

\section{Property Claims, Relations and Obligations}

Thus far we have prestige goods taking on ambiguous forms to create patchwork solutions: Shukudai defusing an argument; Kaido's resolution of oppositional framings of FFXI; and BigWig's axe whose property form may change without altering relations it maintains. Ambiguous property forms help stitch together multiple orderings of people and things, but when objects become neither entirely gift nor commodity, ascertaining appropriate relations between people and things becomes difficult. When 
prestige goods re-enter circulation, players grapple with an old anthropological question: to whom does a person have obligations to give? Alternatively, who may make claims upon an object? The former framing suggests gifts and relations of reciprocity, the latter encompasses both gift and commodity relations. It is in these latter terms that FFXI players think about recirculation. Having briefly examined

355 how, and to some extent why, ambiguity is co-produced, this section explores the relational consequences for people and things of ambiguous property forms.

When items are recirculated, claims are based on myriad ways of ordering people, things and relations.

Faced with nearly irreconcilable differences, linkshell leaders avoid regulating divestments and recirculation. I asked Peep (Gobbue) about the absence of such rules.

Peep: it would be a crazy idea, telling people what to do with their stuff. Nobody could agree. I'll decide who is my friend, who helped me. Like Vim, he's a douche. We [were] in the same LS once. If there had been some rule that said I had to give back all my stuff to the LS if I quit, he'd get most of it because we're both Rangers. That's bullshit. I'd make some massive drama over that. [Author]: So not having rules about this means avoiding arguments?

Peep: No, it's like not making an LS auto-destruct button. Who could even make rules like that? God?

370 Peep equates redistribution rules with dictating the form and nature of socio-material relations. He argues rules forcing him to return prestige goods to the linkshell could mean giving to someone he detests. Rather than owning a relation that does not exist, Peep would fight back. Peep's most important relations of obligation are to friends, to people who 'helped' him. Those ties are stronger than any he might have to a group or linkshell leaders.

Peep also questions whether anyone could develop recirculation rules, invoking 'God' as an entity that could knit together fractal orderings of things and people. Luckily for Peep, FFXI players usually manage to make such partial connections themselves when new property and non-property related 
issues are at stake. The daily round of a FFXI user brings her into contact with hundreds of other

380 gamers, each of whom has their own way of making sense of and engaging with this digital virtual world. To be a player of FFXI is to be a negotiator, settling questions about party organisation and setup, battle procedure and item distribution, or deciding whether to invite someone's best friend, even though there is only one party slot left and that person does not have the right skills, or is the wrong level, or hasn't completed a prerequisite task. Players debate which ways are better or worse, but

385 acknowledge multiple ways of knowing and ordering the game world. Generally, these different worlds can be assembled through negotiation and shared practices - which have themselves been shaped over years of debate and discussion. Fudging categories can be useful for smoothing over differences, but secondary distributions involve objects that have already taken on an ambiguous property form, neither gift not commodity. Once categories have been blurred, relations are in question as well. Reaffirming objects as both gift and commodity as they are being divested - as BigWig did with his axe - becomes a way to manage previous ambiguity while allowing recipients freedom to change an object's form without altering relations through which it flowed.

Conflict within linkshells and between friends over appropriate allocation of goods upon leaving FFXI

395 is not uncommon. Such disputes are as much about objects as relations. Before giving Maneater to Jagermeister, BigWig gave his Kirin's Osode to Fig, who was not in Azalea linkshell. Kirin's Osode is transferable body armour dropped by Kirin, whose appearance requires objects from four other beasts, each of which requires special items collected from a third tier of creatures. The linkshell had fought Kirin four times, winning only thrice, and collecting only two Kirin's Osodes. 
BigWig: but its mine

Jagermeister: u didnt give him ur maneater ?

BigWig: nah thats for u man

Jagermeister: sweeeeeet

R2D2: well thats better

$\mathrm{K}$ : dam[n] strai[gh]t. did u ask mush[room] or death about [the] osode

Kasha: bet he didnt

BigWig: no. cant i give it if i want to?

$\mathrm{K}$ : you should of asked

R2D2: aren't we your friends too?

415

Kasha: guess not R2

Kasha: we[']re just dum[b] nob[o]dys

Kasha: no prob[lem]

When K revealed BigWig's gift to an outsider, Azalea members were angry and confused, but for

420 different reasons. Kasha, R2D2 and K perceive different relations between themselves, BigWig and his

Osode than BigWig does. He perceives his connections to other linkshell members, but for him the

Osode has no such relations, it is an alienated commodity, no one has claims upon it.

For Jagermeister and R2D2, the linkshell has a claim on BigWig's armour, as it was generated through

425 collective effort and because linkshell members are his friends - BigWig met R2D2 and Kasha in

person at a FFXI fan festival, and sometimes they join his Half-Life matches with Jagermeister. In this world ordering, friendship and comradely heroic endeavour are strong relations that create an obligation to give, or at least provide grounds for a collective property claim. A linkshell is obligated to bestow collective wealth as indicated in its rules, whether distribution of new property is linked to a

430 points system or is negotiated in other ways. Thus, when members no longer need goods, they also have an obligation to recirculate. Some respondents phrased this obligation as a moral duty. Strummer described refusal to recirculate goods as 'taking away from the community' - echoing Giesler's (2006:287-288) file-sharer's frustrations with leechers who download but do not share music. K asked whether BigWig consulted with Mushroom and Death, Azalea's founders. For Kasha and K, approval 
and Mushroom become distributors or gatekeepers of prestige items, like Melanesian Big Men. In this world ordering, stronger relations of obligation exist between BigWig and linkshell leaders than between him and the group as a whole, or some other person to whom he might wish to give the Osode.

440 Giving Maneater to Jagermeister was lauded as a good decision because the object remained in Azalea and was given to someone approved by linkshell leaders, as represented by K. Though BigWig admitted he made a mistake, this conflict escalated when a complaint was made to Mushroom. Though Azalea survived this controversy, some members quit. Leaving property obligations unsettled is risky business, but explicit rules would formalise relationships between linkshells and their members by

445 specifying normative relations between people and things. As Peep argued, and the debate over BigWig's Osode divestment illustrates, consensus would be hard to achieve. Fudging categories and making objects distributed through linkshell activities both gift and commodity allows participants to frame objects and relations multiply according to their own ontologies and desired relations. But when objects are recirculated, such patchworks may unravel, revealing conflicting perceptions of things,

450 relations and people.

\section{Conclusion}

This article began with a question: what is ambiguous about ambiguous goods? My aim was not a refutation of 'ambiguous goods'. Rather, I wanted to think carefully about what ambiguity does, how it

455 might be produced and how we can conceptualise it, by exploring ambiguous property forms in FFXI. This is not a functionalist orientation, but an interest in negotiation, local practices, contingencies and social processes that constitute things and people - though I have focused on human agency, as this reflects respondents' own asymmetrical accounts. I also wanted consider how ambiguity might be developed into a multi-dimensional concept for interrogating consumption practices, property forms, 
460 materialities and economic life. Ambiguity as a concept, rather than a category, provides more scope for examining people, things and relations in multiple rather than singular forms. To address these concerns, I made some bold assertions, and have supported them with an analysis of digital virtual prestige goods in Final Fantasy XI.

465 My first contention was that ambiguity is not an innate or a default status; it is produced through sociomaterial entanglements. Making prestige goods both gift and commodity allows players to negotiate their own relationships between people and things. Prestige goods frame the terms of these interactions in various ways, like being alienable or inalienable, fungible or non-fungible, or through social relations embedded in their production. BigWig decided other Azalea members had no relation with his

470 Osode, but K, R2D2 and others perceived themselves as connected to the object. Whilst BigWig continued to play FFXI as an Azalea member, the armour's ambiguous property form could remain unresolved. Diverse orderings of its relations with other things and people could exist in parallel. When the Osode was recirculated, different normative framings of socio-material relations were brought into conflict. Gaps and overlaps between fractal worlds needed to be smoothed over and renegotiated. Peep

475 also highlighted the importance of relations, arguing that making rules about recirculation would mean dictating what relations should exist between linkshell members, leaders and prestige goods. In both instances, ambiguity arises from socio-material entanglements between people and things, it is relational and unstable. We cannot understand why certain categories are made ambiguous by actors in a given setting, through particular objects that may facilitate or resist these efforts, without considering 480 how relations are ordered between people and things in that place, by those actors at a given time.

Players accounts' also reveal that they are not creating new categories, but rather producing contingent, perhaps even temporary, hybrids that bridge ontological differences over well-established categories. 
Thus, ambiguous goods are not a new category of things. Prestige goods gained through linkshells are

485 both gift and commodity, but the balance between the two is negotiable. It is no accident that property forms have become a means of bridging different worlds in FFXI. In consumer capitalist societies property forms are entangled with entire worlds, encompassing moral, material, social and economic sortings of things, relations and people. Property is a fecund category, but sociological conceptual resources are concentrated at extremes. More work is needed on intermediate positions (e.g.: Bird-

490 David and Darr, 2009), and not only between these two property forms. Further research should also explore how objects may resist or facilitate efforts to blur category boundaries (e.g.: Holdbraad 2001; Strathern, 1996a; Jansen 2013).

This brings us to the third point: digital virtual objects are no more or less ambiguous than other goods.

495 Dematerialised entities appear in FFXI as property that takes on ambiguous forms through interactions between things and people. Even a new species lauded as 'previously unknown to science' produces ambiguity because scientists attempt to make this entity fit within Linnaean taxonomy or cladograms. A previously unnamed amphibian goes about its business without much concern for herpetologists struggling to determine how it should be classified. Its relations with others, its position vis-a-vis

500 existing categories, are sources of ambiguities. The importance of relationality strongly suggests consumer culture studies must break free of narrow, dyadic conceptions of gift relations, and simplified notions of giving to a community. As Peep's unwillingness to acknowledge Vim suggests, giving to a 'community' may not include everyone. Some relations within a network of people and things are more privileged than others. Such efforts should engage with ongoing anthropological debates on ceremonial

505 exchange, gifts, property, and relatedness (Bird-David and Darr, 2009; Holdbraad, 2011; Strathern 1991[2005], 1996a, 1996b, 1999; Weiner 1980). 
Virtual objects have different, analytically interesting forms and configurations, but they are not an altogether new form of materiality (see Slater, 2002a for a critical overview). What is most interesting,

510 and analytically fruitful, about digital virtual goods is how they present novel configurations of familiar ideas, categories and concepts. Ambiguity created by blurring categorical distinctions is only one example of old wine in new bottles. Studies of consumer culture have rich explorations of property forms - gifts (Giesler, 2006; Giesler and Pohlmann 2003; Pearson, 2007), commodities (Besnier, 2004; Slater 2002), cherished possessions (Marcoux, 2001; Epp and Price, 2009), singularised goods

515 (Kopytoff, 1986) - and there is a burgeononing literature on intellectual property, creative commons and collaboration. Yet the foundational concept of property remains rather under-emphasised. I have emphasised property as relations, but property as rights yields equally rich analytical materials for exploring category ambiguities, such as ownership and categories of possession. Changing consumption practices and technologies are reconfiguring the contours of property, both as relations

520 and as rights. This is an interesting time to be thinking critically about how property - as a classificatory category, as an everyday practice, as a way of ordering relations - is being produced, reproduced and maintained in consumer capitalist societies.

\section{Acknowledgements}

Feedback and comments from Don Slater, Daiana Beitler, Lili di Putto and Aigul Mavletova improved an early draft of this article. Constructive, insightful comments from anonymous reviewers and the editors were also appreciated.

\section{References}

Appadurai, A. 1986. Introduction, in The Social Life of Things: Commodities in Cultural Perspective, Appadurai, A. (ed). Cambridge: Cambridge University Press; 3-63.

Bauman, Z. 2001. Consuming life. Journal of Consumer Culture 1(1):9-29.

535 DOI:10.1177/146954050100100102.

Belk, R. 2010. Sharing. Journal of Consumer Research. 36(5):715-734. 
Belk, R., Wallendorf, M. and Sherry, J. 2004. The Sacred and the Profane in Consumer Behavior. 540 Journal of Consumer Research. 16(1):1-38

Besnier, N. 2004. Consumption and Cosmopolitanism: Practicing Modernity at the Second-Hand Marketplace in Nuku'alofa, Tonga. Anthropological Quarterly 77(1):7-45.

545 Bird-David, N and Darr, A. 2009. Commodity, gift and mass-gift: on gift-commodity hybrids in advanced mass consumption cultures. Economy \& Society. 38(2):304-325.

Carrier, J. 1991. Gifts, Commodities, and Social Relations: A Maussian View of Exchange. 6(1):119136.

550

Carrier, J. 1995. Gifts and Commodities. London: Routledge.

Denegri-Knott, J and Molesworth, M. 2012. Introduction to digital virtual consumption, in Digital Virtual Consumption, Molesworth, M and Denegri-Knott, J. (eds). London: Routledge; 1-8.

555

Douglas, M. and Isherwood, B. [1979]1996. The World of Goods. London: Routledge.

Durkheim, É. [1902]1960. The Division of Labor in Society. Glencoe: Free Press.

560 Epp, A. and Price, L. 2009. The storied life of singularized objects. Journal of Consumer Research. 36(5):820-837.

Giesler, M. 2006. Consumer gift systems. Journal of Consumer Research. 33 (2):283-290.

DOI:10.1086/506309

565

Giesler, M and Pohlmann, M. 2003. The anthropology of file sharing: Consuming Napster as gift. Advances in Consumer Research. 30:273-279

Holdbraad, M. 2011. Can the thing speak? Open Anthropology Collective Working Papers Series. \#7

http://openanthcoop.net/press/2011/01/12/can-the-thing-speak/ [accessed April 12 2013]

Jansen, S. 2013. People and things in the ethnography of borders: Materialising the division of Sarajevo. Social Anthropology 21(1):23-37.

575 Kopytoff, I. 1986. The cultural biography of things, in The Social Life of Things: Commodities in Cultural Perspective, Appadurai, A. (ed). Cambridge: Cambridge University Press; 64-91.

Law, J. 2011. What's wrong with a one-way world. Available at http://www.heterogeneities.net/publications/Law2011WhatsWrongWithAOneWorldWorld.pdf

$580 \quad$ [accessed 12 February 2013].

Law, J and Mol, A. 1995. Notes on materiality and sociality. The Sociological Review. 43(2):274-294. DOI: 10.1111/j.1467-954X.1995.tb00604.X

585 Lehdonvirta, V. 2010. Virtual Worlds Don't Exist: Questioning the Dichotomous Approach in MMO 
Studies. Game Studies. 10(1). http://gamestudies.org/1001/articles/lehdonvirta [accessed September 15 2013]

Linebaugh, P and Rediker, M. 2000. The Many-headed Hydra. London: Verso.

Marcoux, J. 2001. The caisser-maison ritual: Constructing the self by emptying the home. Journal of Material Culture 6(2):213-235.

Mauss, M. [1954]1970. The Gift: Forms and Functions of Exchange in Archaic Societies. Cunnison, I. 595 (trans.) London: Cohen \& West.

Parsons, E. and Maclaran, P. 2009. 'Unpacking disposal': introduction to the special issue. Journal of Consumer Behaviour. 8(6):301-304.

600 Pearson, E. 2007. Digital gifts: Participation and gift exchange in Live Journal communities. First Monday. 12 (5). http://firstmonday.org/ojs/index.php/fm/article/view/1835 [accessed June 10 2013]

Ross, S. 2012. Playing the market and sharing the loot, in Digital Virtual Consumption, M. Molesworth and J. Denegri-Knott (eds.). London: Routledge; 146-160.

Slater, D. 2002. Markets, materiality and the 'new economy', in Market Relations and the Competitive Process, S. Metcalfe and A. Warde (eds.). Manchester University Press: Manchester; 95-113.

Shields, R. 2003. The Virtual. London: Routledge.

Strathern, M. [1991]2005. Partial Connections. Oxford: Altamira Press.

Strathern, M. 1996a. Cutting the network. Journal of the Royal Anthropological Institute 2(3):517-535.

615 Strathern, M. 1996b. Potential property: intellectual rights and property in persons. Social Anthropology 4(1):17-32. DOI:10.1111/j.1469-8676.1996.tb00311.x

Strathern, M. 1999. Property, Substance and Effect. London: Athalone Press.

620 Thompson, E. 1971. The moral economy of the English crowd in the eighteenth century. Past \& Present. 50(2):76-136.

Trentman, F. 2009. Crossing Divides: Consumption and Globalization in History. Journal of Consumer Culture 9(2):187-220. DOI:10.1177/1469540509104374

Weiner, A. 1980. Reproduction: a replacement for reciprocity. American Ethnologist 7(1):71-85. DOI:10.1525/ae.1980.7.1.02a00050 
i Detailed consideration of FFXI's rather Byzantine material world is beyond the scope of this paper, as is a more nuanced discussion of technological affordances, both at the systemic level of FFXI as a massively multi-player online role-playing game, and at the micro-material level of what can and cannot be done with things, characters, people and code in-world. 